\title{
Basic Potential of Carbon Nanotubes in Tissue Engineering Applications
}

\author{
Hisao Haniu, ${ }^{1}$ Naoto Saito, ${ }^{2}$ Yoshikazu Matsuda, ${ }^{3}$ Tamotsu Tsukahara, ${ }^{4}$ Yuki Usui, ${ }^{5}$ \\ Nobuyo Narita, ${ }^{6}$ Kazuo Hara, ${ }^{6}$ Kaoru Aoki, ${ }^{6}$ Masayuki Shimizu, ${ }^{6}$ Nobuhide Ogihara, ${ }^{6}$ \\ Seiji Takanashi, ${ }^{6}$ Masanori Okamoto, ${ }^{6}$ Shinsuke Kobayashi, ${ }^{6}$ Norio Ishigaki, ${ }^{6}$ \\ Koichi Nakamura, ${ }^{6}$ and Hiroyuki Kato ${ }^{6}$
}

${ }^{1}$ Institute of Carbon Science and Technology, Shinshu University, 3-1-1 Asahi, Matsumoto, Nagano 390-8621, Japan

${ }^{2}$ Department of Applied Physical Therapy, Shinshu University School of Health Sciences, 3-1-1 Asahi, Matsumoto, Nagano 390-8621, Japan

${ }^{3}$ Clinical Pharmacology Educational Center, Nihon Pharmaceutical University, 10281 Komuro, Ina-Machi, Saitama 362-0806, Japan

${ }^{4}$ Department of Integrative Physiology and Bio-System Control, Shinshu University School of Medicine, 3-1-1 Asahi, Matsumoto, Nagano 390-8621, Japan

${ }^{5}$ Research Center for Exotic Nanocarbons, Shinshu University, 3-1-1 Asahi, Matsumoto, Nagano 390-8621, Japan

${ }^{6}$ Department of Orthopaedic Surgery, Shinshu University School of Medicine, 3-1-1 Asahi, Matsumoto, Nagano 390-8621, Japan

Correspondence should be addressed to Hisao Haniu, hhaniu@shinshu-u.ac.jp

Received 9 December 2011; Revised 4 February 2012; Accepted 4 February 2012

Academic Editor: Raquel Verdejo

Copyright () 2012 Hisao Haniu et al. This is an open access article distributed under the Creative Commons Attribution License, which permits unrestricted use, distribution, and reproduction in any medium, provided the original work is properly cited.

\begin{abstract}
Carbon nanotubes (CNTs) are attracting interest in various fields of science because they possess a high surface area-to-volume ratio and excellent electronic, mechanical, and thermal properties. Various medical applications of CNTs are expected, and the properties of CNTs have been greatly improved for use in biomaterials. However, the safety of CNTs remains unclear, which impedes their medical application. Our group is evaluating the biological responses of multiwall CNTs (MWCNTs) in vivo and in vitro for the promotion of tissue regeneration as safe scaffold materials. We recently showed that intracellular accumulation is important for the cytotoxicity of CNTs, and we reported the active physiological functions CNTs in cells. In this review, we describe the effects of CNTs in vivo and in vitro observed by our group from the standpoint of tissue engineering, and we introduce the findings of other research groups.
\end{abstract}

\section{Introduction}

Carbon nanotubes (CNTs) were first reported by Oberlin et al. [1], and Iijima's report [2] subsequently generated a great deal of interest in CNT research. CNTs consist of rolled, single, or multiple graphene sheets that form singled-walled CNTs (SWCNTs) and multi-walled CNTs (MWCNTs), with nanometer diameters and a high aspect ratio (above 100). CNTs have unique physicochemical properties, different from those of other carbon allotropes, such as graphite, diamond, and fullerenes. Three major production methods are currently used to manufacture CNTs, including arc discharge, laser ablation, and chemical vapor deposition (CVD). The CVD method particularly enabled the mass production of CNTs, and effective purification methods were also improved to prevent structural damage and remove the metals that are used as catalysts during CNT production [3]. Figure 1 shows highly purified MWCNTs with a mean diameter of $100 \mathrm{~nm}$ and a mean length of $10 \mu \mathrm{m}$ prepared by the CVD method.

Because of their unique physical, mechanical, and electronic properties, CNTs are valuable as reinforcements or additives to improve the properties and introduce novel functionalities of various materials in a number of fields, including chemistry, electronics, energy, and materials science [4]. The unique properties of CNTs have also attracted attention from the medical and biological fields, and the application of CNTs as biomaterials is expected for biosensors, drug and 


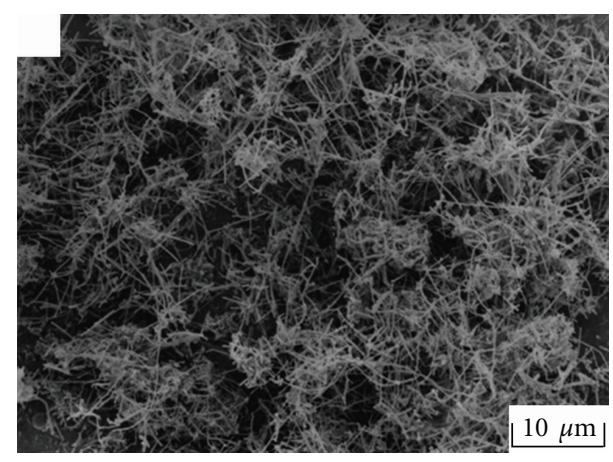

(a)

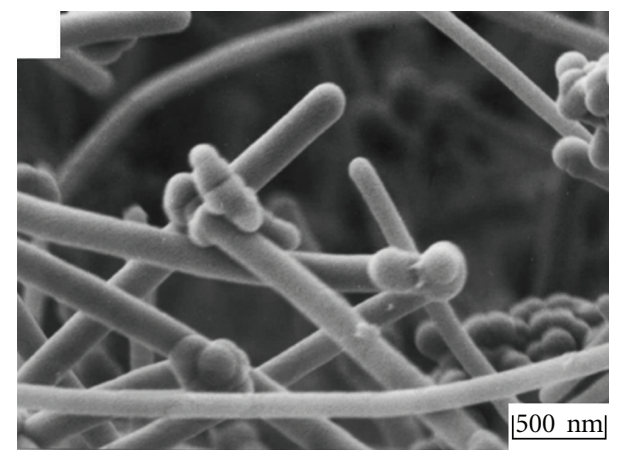

(b)

FIGURE 1: Field-emission scanning electron microscope image of VGCFs at 2 different resolutions [3].

vaccine delivery vehicles, and scaffold materials [5]. CNTs have limited solubility in aqueous media, which presents a drawback for medical and biological applications; however, this problem is being solved by the addition of chemical functional groups to the side walls and tips of the CNTs.

In addition, CNTs possess asbestos-like features (i.e., a nanoscale size and a high aspect ratio). Thus, CNTs may be hazardous to human health and the environment $[6,7]$. In 2008, Takagi et al. reported that transgenic mice injected intraperitoneally with MWCNTs exhibited mesothelioma similar to that in mice exposed to asbestos [8]. Subsequently, other investigators investigated the safety of the inhalation or intratracheal administration of MWCNTs in vivo, and pleural mesothelioma and lung cancer were not induced [9-13]. In 2010, the National Institute for Occupational Safety and Health (NIOSH) presented guidelines for occupational exposure and indicated the safety level that did not result in tumorigenesis [14]. NIOSH is recommending an exposure limit of $7 \mu \mathrm{g} / \mathrm{m}^{3}$ elemental carbon as an 8 -h time-weighted average respirable mass airborne concentration. We evaluated the safety of MWCNTs, and the clarification of toxic mechanism is currently underway [15-19]. It appears that CNTs do not cause acute critical diseases unless the intracellular accumulation of CNTs passes a certain limit.

CNTs do not only present a biological hazard; they have been shown to have positive effects in the human body. Some studies have already described favorable medical applications of functionalized CNTs [21-25], and most of the observed effects depend on the functional groups added to the CNTs. Therefore, this review describes the potential of plain CNTs as a biomaterial for tissue engineering.

\section{Relationship between CNTs and Cells}

The relationship between CNTs and cells has been studied from 2 aspects: efficacy and safety. CNTs have also been studied in terms of functionalization and mixing with other materials. The development of CNT-based drug and gene delivery systems, as well as imaging techniques, is based on the functionalization of the CNTs [26-28], particularly their endocytosis. Pantarotto et al. demonstrated that ammonium-functionalized CNTs interacted with the phosphate groups of plasmid DNA, penetrated cell membranes, and were taken up into the cells with little cytotoxicity [29]. However, the cytotoxicity was not evaluated after the CNTs were endocytosed. The cytotoxicity evaluation that was performed only evaluated the toxicity for 1 or $3 \mathrm{~h}$, and it only evaluated the penetration risk of the CNTs. To investigate the relationship between the cytotoxicity and intracellular accumulation of CNTs, we exposed 2 different cell lines to MWCNTs for $24 \mathrm{~h}$ and assayed the cytotoxicity and volume of the intracellular CNTs [16]. The intracellular accumulation of the CNTs and the cytotoxicity were correlated; when the accumulation exceeded a certain level, the CNTs showed cytotoxicity. Hirano et al. also demonstrated the cytotoxicity of CNT uptake using human bronchial epithelial cells (BEAS-2B) [30]. In contrast, Giannona et al. and Lopo et al. reported that the CNT films and scaffolds were biocompatible with cultured cells because they were not endocytosed by the cells [31-35]. We found that the endocytosis of CNTs varied according to the dispersant and the cell line $[16,17]$. Cells with phagocytic activity endocytosed even plain CNTs, which are not functionalized or hydrophilic. These findings suggest 2 critical points for the medical application of CNTs using the phagocytic activity of cells: (1) the quantity of intracellularly accumulated CNTs must be controlled and (2) the affinity of functionalized CNTs for the targeted cells is critical. The affinity to the target cells of the functional groups linked to the CNT must be higher than the affinity of the cells for CNT itself, because most cells adhere to CNTs [17]. Liu et al. conjugated SWCNTs with targeting ligands, including peptides and antibodies for specific cell labeling in vitro or tumor targeting in vivo. These functionalized SWCNTs were highly endocytosed by the cells that expressed the receptor for the ligand [36]. However, their in vitro experiment did determine whether the U87MG cells that they used expressed the receptor or endocytosed plain SWCNTs, and it is likely that endocytosis would also occur in other organs or tissues. Furthermore, the potential cytotoxicity of these functionalized CNTs must be investigated at the concentrations used for such experiments.

\section{Active Effects of CNTs on Cellular Function}

Most studies of the potential therapeutic effects of CNTs have focused on bone. There are some reports on the use of 


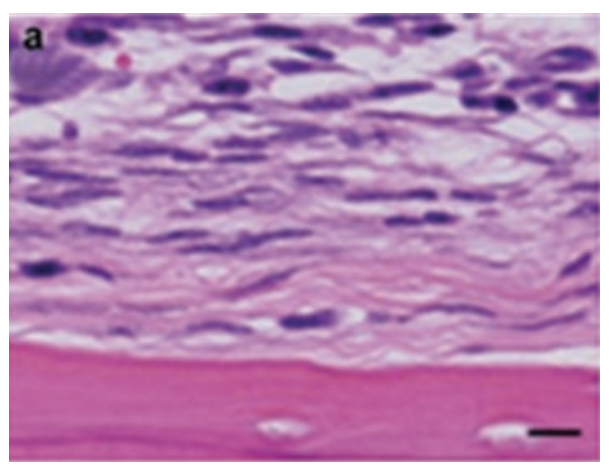

(a)

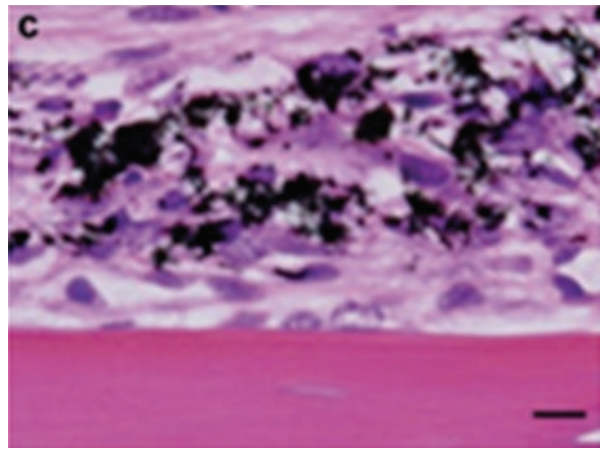

(c)

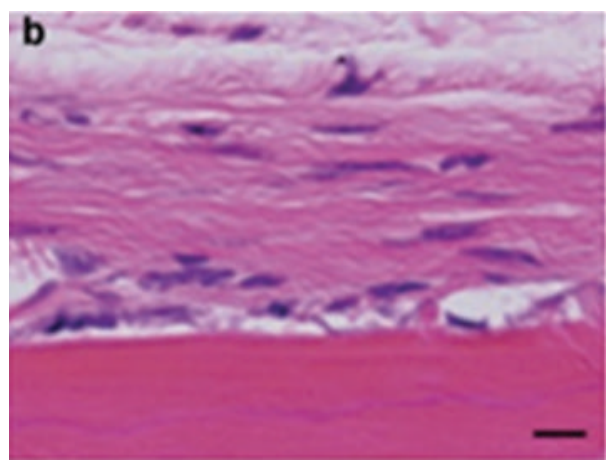

(b)

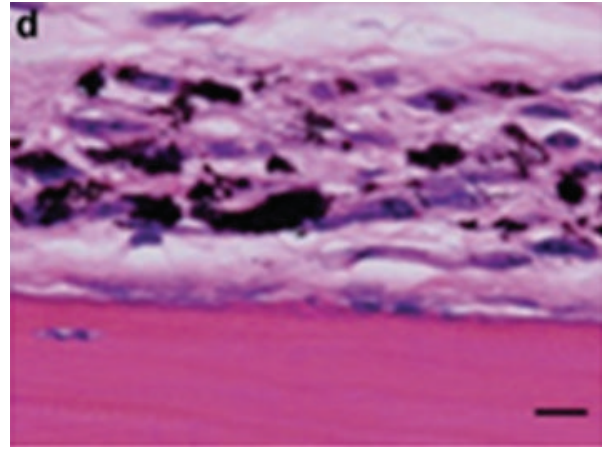

(d)

Figure 2: MWCNTs showed good bone-tissue compatibility, induced little inflammatory reaction, and had little effect on the adjacent bone tissue when implanted into the subperiosteum. The histologic appearance of the subperiosteal skull is shown for mice from (a, b) the sham operation group, where a subperiosteal pocket was made but only vehicle solution was implanted, and (c, d) the MWCNT group at 1 week and 4 weeks after the operation. (a) The periosteum was essentially restored, and the inflammatory reaction was minimal. (b) The periosteum was completely restored. (c) The periosteal tissue showed the same degree of restoration as in the sham operation group. MWCNT particles remained subperiosteal, and the inflammatory reaction was minimal. Macrophages were seen surrounding the MWCNT particles. (d) The periosteal tissue was restored completely and still contained MWCNT particles and macrophages. The inflammatory reactions were decreased compared with those after 1 week. The cortical bone beneath the implant was preserved. Hematoxylin and eosin staining. Scale bars: $20 \mu \mathrm{m}[20]$.

CNTs for scaffolds in bone regeneration [38-40]. However, these reports evaluated composites containing CNTs, and it is difficult to determine the effects specifically mediated by the CNTs. Few reports on the direct influence of CNTs on bone are available. Zanello et al. reported that osteosarcoma ROS 17/2.8 cells cultured on CNTs showed suppression of cell growth, production of plate-shaped crystals, and a dramatic change in cell morphology [41]. Mwenifumbo et al. investigated the influence of nanoscaled dimensions on human osteosarcoma (Saos-2) cells [42] and found that cells grown on MWCNT constructs showed higher metabolic activity and a disorganized actin cytoskeleton. Both studies consider the biological responses to be positive, but the evaluation requires attention. Some crystallization occurs on CNTs without cells [43, 44], and the MTT [3-(4,5-dimethylthiazol-2-yl)-2,5-diphenyl-tetrazolium bromide] assay for cell metabolic activity is not suitable for the experiments with CNTs $[45,46]$.

Our group showed that CNTs are highly biocompatible and accelerate osteogenesis in vivo [20]. Mice were implanted with MWCNTs in the subperiosteum of the skull or in tibial defects that were generated experimentally to evaluate bone tissue compatibility. At 1 and 4 weeks after implantation, the MWCNT group showed the same degree of tissue restoration and inflammation as in the sham operation group (Figure 2). Moreover, ectopic bone formation was also demonstrated in response to recombinant human bone morphogenetic protein-2 (rhBMP-2) delivered using collagen with or without MWCNTs. The rhBMP-2-collagenMWCNT group showed larger bone shadows with soft X-ray analysis and a significantly higher bone mineral content. We initially examined the influence of MWCNTs on osteoclasts to clarify the mechanism of the acceleration of osteogenesis by the MWCNTs [37]. We showed that MWCNTs inhibit osteoclastic bone resorption in vivo and that MWCNTs inhibit osteoclastic differentiation and suppress the expression of a transcription factor essential for osteoclastogenesis in vitro (Figure 3). We are currently evaluating the influence of MWCNTs on osteoblasts. Our studies suggest that plain CNTs have a direct influence on osteogenic cells.

The effects of CNTs have also been reported for other tissue types. The nervous system is also a target for CNTs used as biomaterials, because CNTs are strong, flexible, and have high conductivity. The first study in this field was 

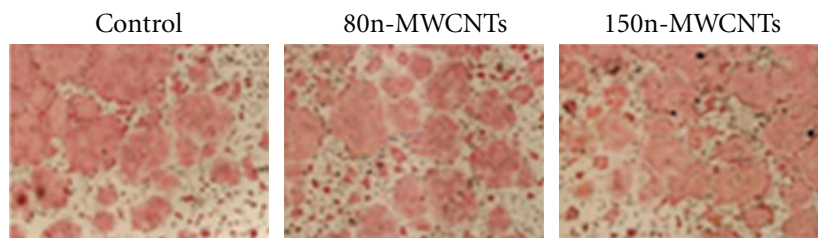

(a)

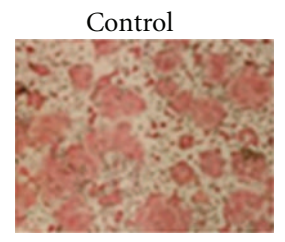

\section{0n-MWCNTs}

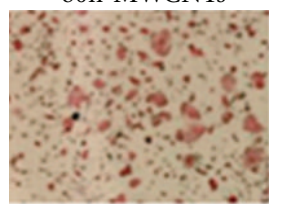

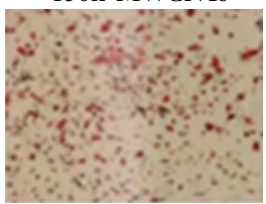

150n-MWCNTs

\section{$\mathrm{CB} \quad(5 \mu \mathrm{g} / \mathrm{mL})$}

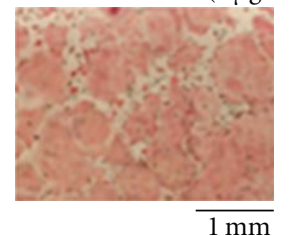

$1 \mathrm{~mm}$

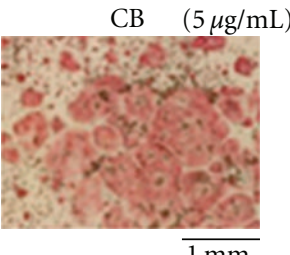

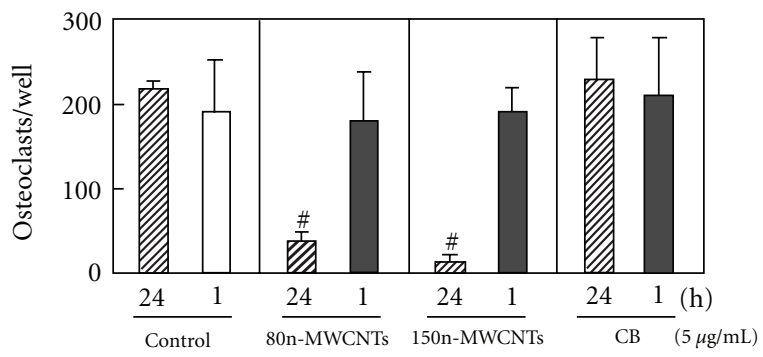

(b)

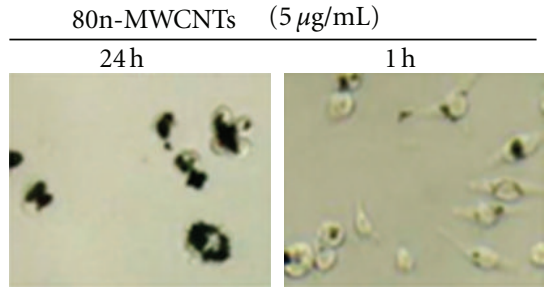

$(5 \mu \mathrm{g} / \mathrm{mL})$

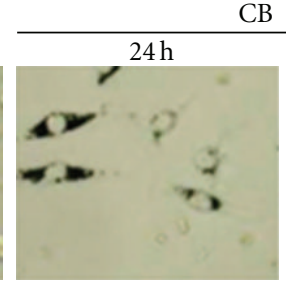

(c)

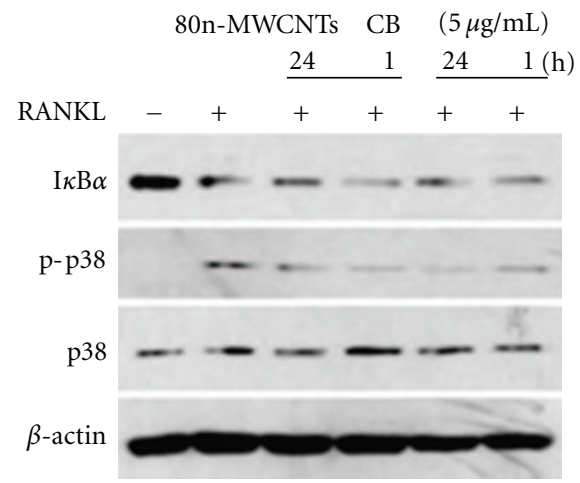

(d)

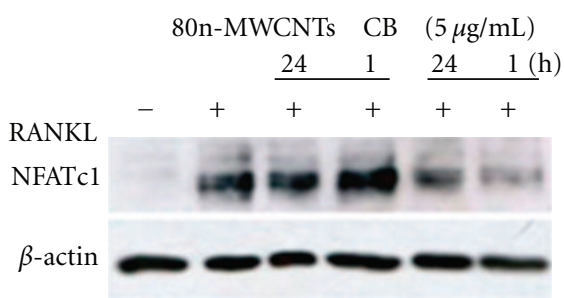

(e)

FIGURE 3: MWCNTs incorporated into bone-marrow-derived macrophages (BMM $\varphi$ ) inhibited the differentiation of $\mathrm{BMM} \varphi$ into osteoclasts. (a) $\mathrm{BMM} \varphi$ were cultured for 3 days with receptor activator of nuclear factor- $\kappa \mathrm{B}$ ligand (RANKL, $100 \mathrm{ng} / \mathrm{mL}$ ) and macrophage colony stimulating factor (M-CSF, $25 \mathrm{ng} / \mathrm{mL}$ ) in the presence or absence of 80n-MWCNTs, 150n-MWCNTs, or carbon black (CB). Cells were fixed and stained for TRAP. $n=4$. (b) BMM $\varphi$ were treated with or without 80n-MWCNTs, 150n-MWCNTs, or CB for 24 or 1 h. BMM $\varphi$ were further cultured for 3 days in the presence of RANKL $(100 \mathrm{ng} / \mathrm{mL})$ and M-CSF $(25 \mathrm{ng} / \mathrm{mL})$, fixed, and stained for TRAP. $n=4$. \#; $P<0.001$ versus control. (c) Phase-contrast microscopy of BMM $\varphi$ treated with 80 n-MWCNTs or $\mathrm{CB}$. BMM $\varphi$ were incubated for 24 h with 80n-MWCNTs or CB, fixed, and observed under a phase-contrast microscope. (d, e) Neither 80n-MWCNTs nor CB attenuated RANKLinduced signals in $\operatorname{BMM} \varphi$. BMM $\varphi$ were cultured with or without $80 \mathrm{n}-\mathrm{MWCNT}$ or $\mathrm{CB}$ under the same conditions as in the experiments in (b). BMM $\varphi$ were then treated for 20 min with RANKL $(100 \mathrm{ng} / \mathrm{mL})$ to activate NF- $\kappa$ B and p38 MAPK (d). BMM $\varphi$ were treated with RANKL $(100 \mathrm{ng} / \mathrm{mL})$ for $24 \mathrm{~h}$ to induce NFATc1 (e). Cell lysates were subjected to SDS-PAGE, followed by immunoblotting with specific antibodies [37]. 
Oil red O
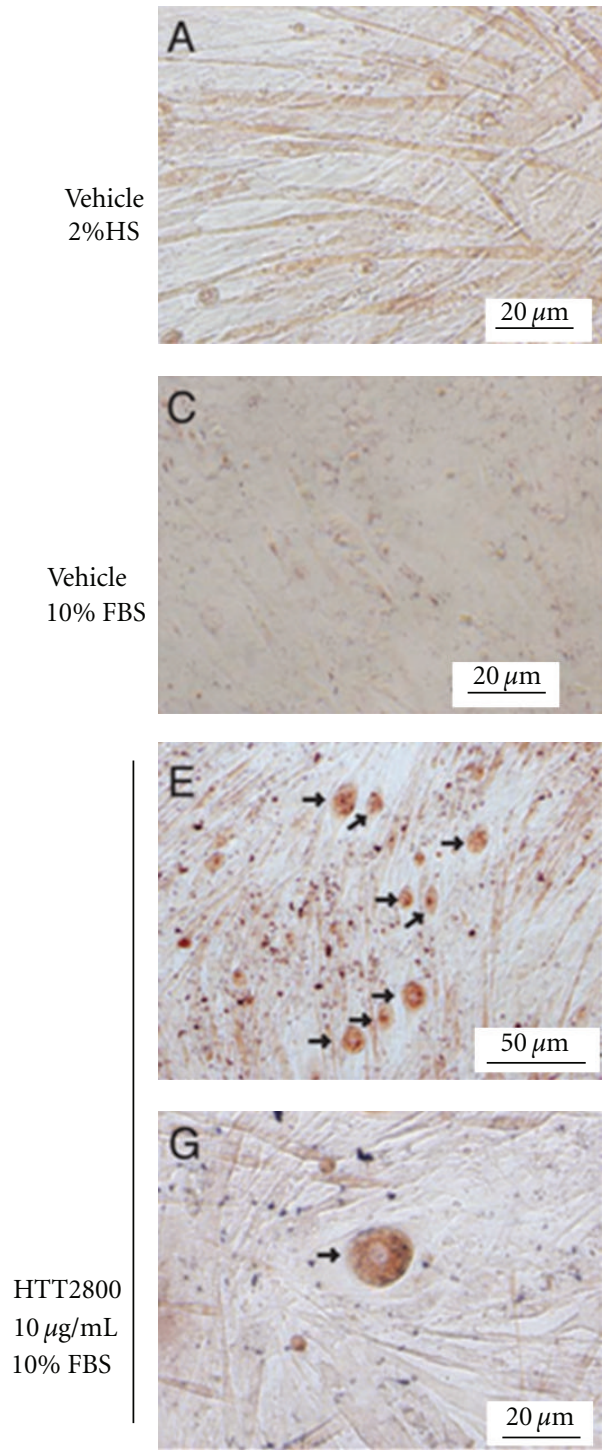
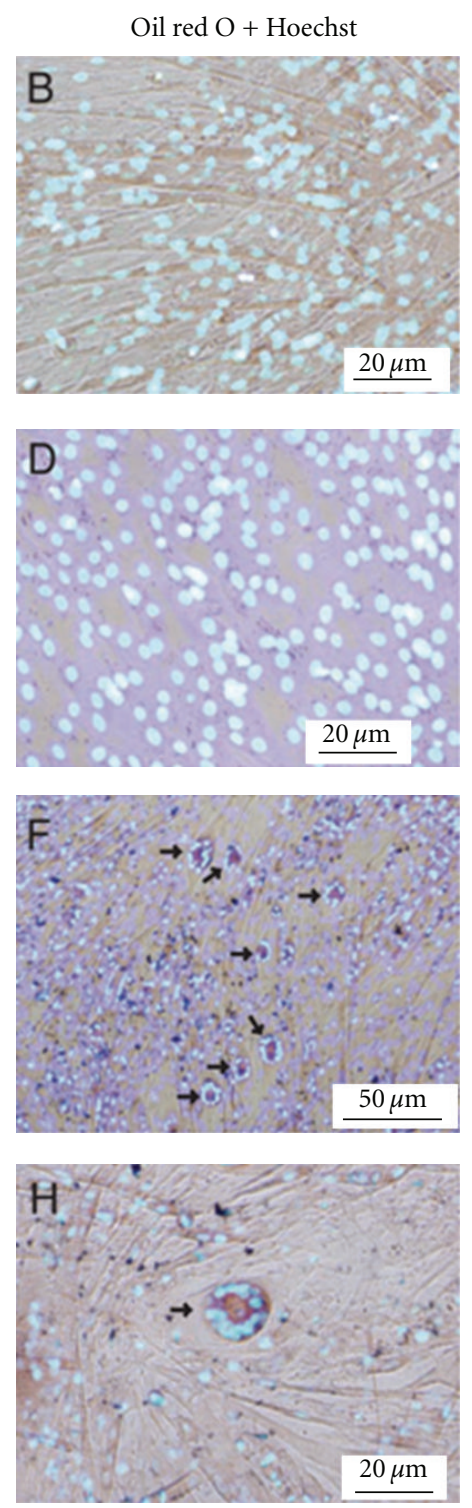

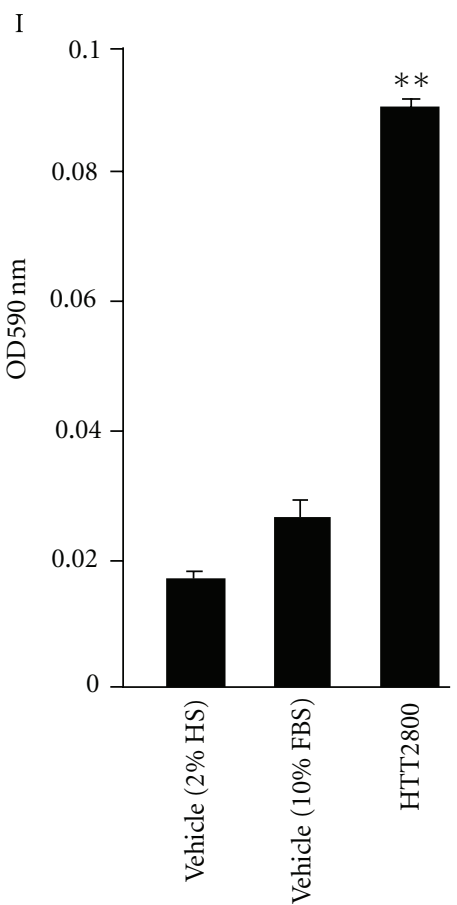

FIGURE 4: MWCNT treatment induces cellular lipid accumulation in C2C12 cells. Cells were treated with 2\% horse serum (HS) (A) and $10 \%$ FBS (C) or $10 \mu \mathrm{g} / \mathrm{mL}$ MWCNT (E and G) for 7 days after the cells reached 70-80\% confluence. Oil red O staining was performed after 7 days of exposure to the growth medium. The arrows indicate cells positive for lipid droplet content. Cell nuclei (indicated as black arrows) stained with Hoechst 33342 (blue) were visualized on day 7 by using a fluorescent microscope (B, D, F, and H). (I) Lipid accumulation was quantitatively assayed with a lipid-staining reagent to evaluate the lipid content [47].

reported by Mattson et al. in 2000 [48]; a lack of effect by unmodified CNTs was demonstrated where neurons grown on CNTs coated with 4-hydroxynonenal exhibited multiple neurites and extensive branching. Subsequent studies also showed beneficial effects of functionalized CNTs, and although plain CNTs have not been shown to have negative effects [49-53], no beneficial effect on cellular function has been reported. We also evaluated the effects of MWCNTs on IMR-32 human neuroblastoma cells [17], which did not internalize MWCNTs. The MWCNTs only bound to the cells without cytotoxicity. Unmodified CNTs seem to have low cytotoxicity and high biocompatibility but do not seem to affect the nerve system actively.
Li et al. [55, 56] pressed MWCNTs as compacts and adsorbed proteins on them before cell culture. Mouse myoblastic (C2C12) cells cultured on the compacts differentiated into osteogenic cells, and Saos-2 cells underwent osteogenic maturation. Li et al. suggest that the adsorption of specific proteins to CNTs is critical. We also cultured C2C12 cells with MWCNTs without specific pretreatment [47]. The MWCNT treatment induced cellular lipid accumulation (Figure 4) and the upregulation of specific markers of adipocyte differentiation without cytotoxicity in $\mathrm{C} 2 \mathrm{C} 12$ cells (Figure 5). Although we used gelatin as a dispersant, gelatin did not seem to play a critical role in the differentiation [16]. MWCNTs were endocytosed by the cells, but it remains 


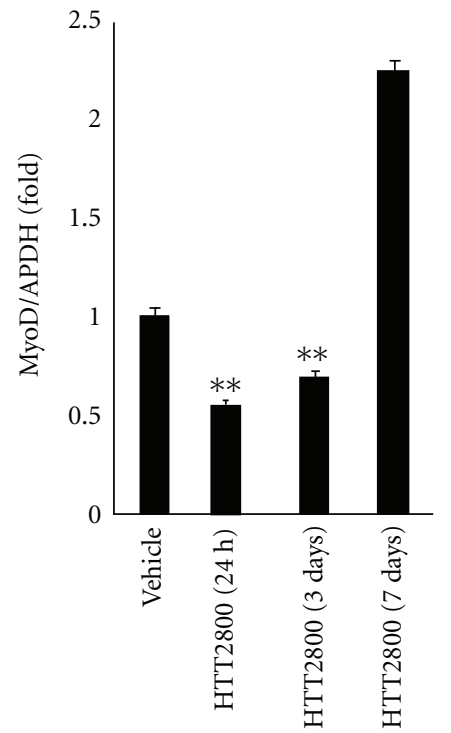

(a)
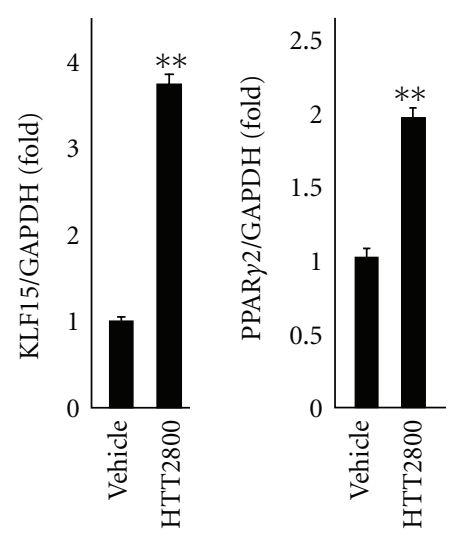

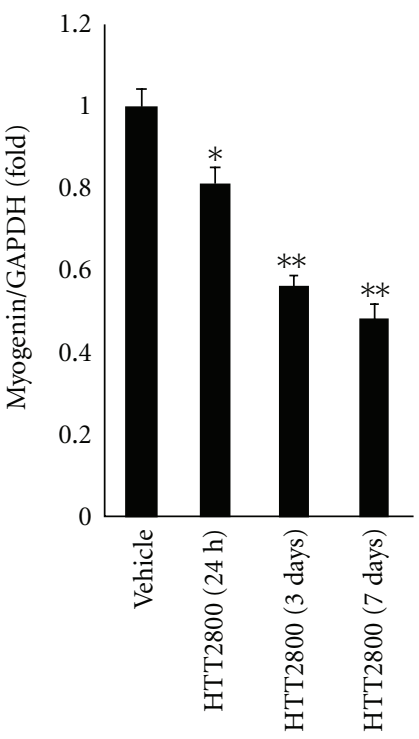

(b)

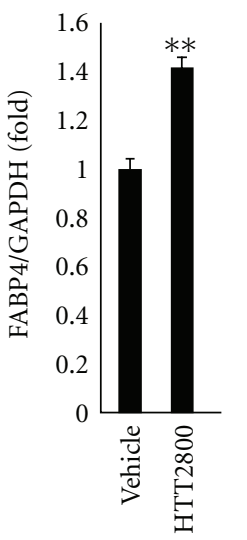

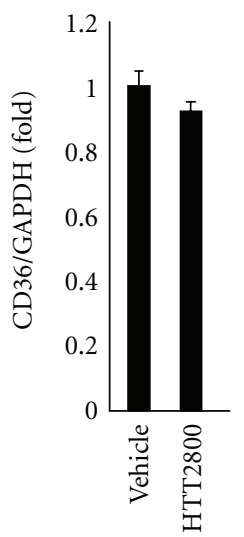

(d)

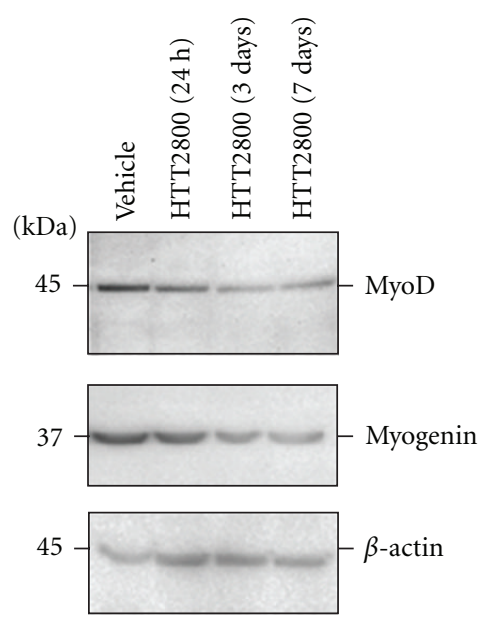

(c)

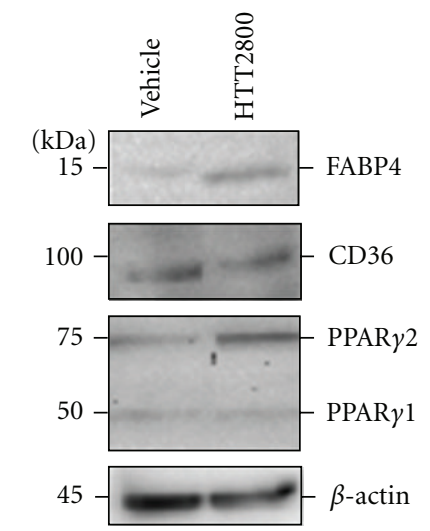

(e)

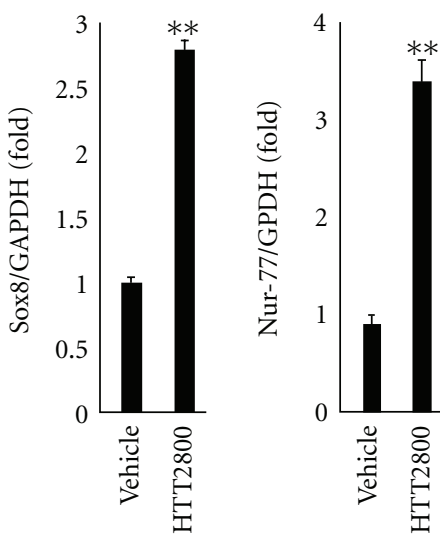
.

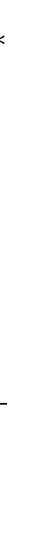


unclear whether the endocytosis of MWCNTs is necessary for the differentiation. However, this is the first report that plain CNTs without any pretreatment actively affected the cellular function and may thus contribute to tissue regeneration directly.

\section{CNTs for Scaffold Materials in Tissue Regeneration}

Scaffolds for tissue regeneration require properties such as rigidity to bear external force, biodegradability and absorption, the ability to promote the adhesion and proliferation of cells, and the ability to be penetrated by blood vessels and body fluids. To date, CNTs have been used to reinforce the weak points of existing scaffold materials. For example, a composite between collagen, which is the most commonly used scaffold material, and CNTs showed good mechanical characteristics because of the favorable properties of CNTs [57-60]. Lobo et al. also reported favorable biocompatibility of CNTs in comparative cytocompatibility studies on vertically aligned (VA) superhydrophobic CNT films functionalized by pulsed-direct current oxygen plasma [61-63]. Furthermore, synthetic biocompatible polymers can be combined with CNTs and evaluated as scaffolds for tissue regeneration. Zhang et al. reported that a composite of poly $\left(\mathrm{L}^{-}\right.$ lactide) and MWCNT showed increased direct-current conductivity, crystallization, plasticization of the polymer matrix, and growth inhibition of fibroblast cells [64]. McCullen et al. fabricated electrospun nanocomposite scaffolds by encapsulating MWCNTs in poly(lactic acid) (PLA) nanofibers [65]. The composite showed reduced fiber diameter and increased conductivity compared with PLA alone. Moreover, adipose-derived human mesenchymal stem cells (hMSCs) on the composite showed increased cell growth and were closely packed and longitudinally aligned at 14 days. Although the responses of the hMSCs appear to be a direct positive effect of the CNTs, it is more likely that these effects were mediated by the difference in pore size between the PLA-CNT composite and PLA alone, which in turn resulted from a difference in the fiber diameter. CNTs have also been used in composites with other biomaterials [66, 67]. Abarrategi et al. fabricated MWCNT-chitosan (CHI) scaffolds composed of MWCNTs (up to $89 \%$ by weight) and $\mathrm{CHI}$ and evaluated the biological responses on $\mathrm{C} 2 \mathrm{C} 12$ cells [68]. The biocompatibility was high in vitro and in vivo, and the composite was biodegradable. However, the MWCNT-CHI scaffold absorbed rhBMP-2 was compared with MWCNT-CHI alone in vitro; no comparison was made with other scaffold materials. Biodegradability was defined as the biodegradation of the scaffold in vivo and not the biodegradability of the CNT itself.

Scaffolds using CNTs have thus been applied to augment the physical properties of the based biomaterials or to provide new properties (e.g., conductivity). However, the biological responses to the added CNTs are similar to those of the base biomaterials; few actual beneficial effects have been observed thus far. Rather, it seems that the change in the physical properties of the composite results in a structural

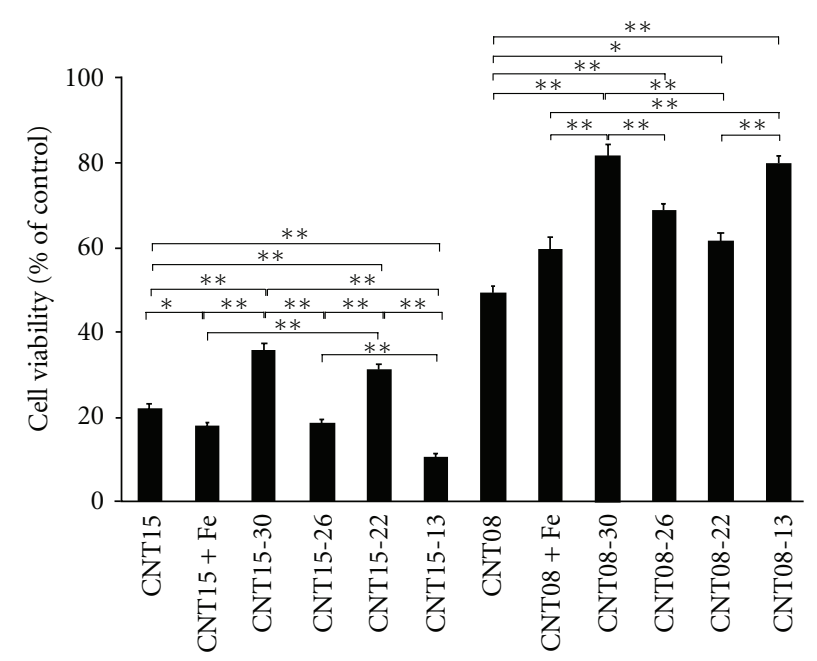

Figure 6: Viability of BEAS-2B cells treated with different MWCNTs. The cells were exposed to MWCNTs for $24 \mathrm{~h}$. The graph shows the cell viability associated with $10 \mu \mathrm{g} / \mathrm{mL}$ of each MWCNT in the MWCNT-150 and MWCNT-80 series (mean \pm SE, $n=6$, $\left.{ }^{*} P<0.05,{ }^{* *} P<0.01\right)$. The table shows the basic properties of the MWCNTs [54].

change of the scaffold and thereby improves biocompatibility. When CNTs are added to the scaffold materials, negative influences have not been reported; however, one unsolved problem remains: the safety of CNTs remains unclear. Because CNTs are biopersistent [69-72] and the cytotoxicity results from the accumulation of $\mathrm{CNT}$ in the cells, the CNTs need to be excreted or biodegraded after absorption in the body. In scaffold biomaterials, biodegradability and bioabsorbability are required after the safety is confirmed.

\section{Conclusion and Perspectives}

CNTs can be used for the reinforcement of biomaterials to substitute hard tissues. The composites of CNTs and ceramics are mainly used for this purpose [73-75]. Because these composites do not need to be degraded and contact with cells directly, it is not necessary to consider the toxicity [35]. However, CNTs may also be used for biosensors, drug and vaccine delivery vehicles, and scaffold materials. The influence of CNTs on these target tissues or cells has not been extensively studied. Toxicologists have focused on the safety of CNTs in the respiratory system because the shape of the CNTs resembles that of asbestos. To successfully apply CNTs in the biomedical field, including tissue engineering, it is necessary to investigate the biodistribution of CNTs used as biomaterials [76] and evaluate their influence on organs or tissues. It seems that the development of CNTs with almost no hazard to human health is possible, because it has been reported that the physical properties (length, thickness, rigidity) of the CNTs greatly contribute to their toxicity [7, $77,78]$. Recently, we indicated that the risk of toxicity could be decreased by improving the manufacture process without modifying the CNTs (Figure 6) [54]. Moreover, Liu et al. reported that single-walled nanotubes with carboxylated 
surfaces are unique in their ability to undergo 90-day degradation in a phagolysosomal stimulant [79]. Further research on the minimization of the risk and maximization of the benefit of CNTs is, therefore, necessary.

\section{Acknowledgments}

The authors thank the staff of the Division of Instrumental Analysis in the Research Center for Human and Environmental Sciences of Shinshu University for their help. This research was supported by the Program for Fostering Regional Innovation in Nagano and a Grant-in-Aid (no. 19002007) from the Ministry of Education, Culture, Sports, Science and Technology of Japan.

\section{References}

[1] A. Oberlin, M. Endo, and T. Koyama, "Filamentous growth of carbon through benzene decomposition," Journal of Crystal Growth, vol. 32, no. 3, pp. 335-349, 1976.

[2] S. Iijima, "Helical microtubules of graphitic carbon," Nature, vol. 354, no. 6348, pp. 56-58, 1991.

[3] M. Endo, Y. A. Kim, T. Hayashi et al., "Vapor-grown carbon fibers (VGCFs) - basic properties and their battery applications," Carbon, vol. 39, no. 9, pp. 1287-1297, 2001.

[4] M. Endo, M. S. Strano, and P. M. Ajayan, "Potential applications of carbon nanotubes," Topics in Applied Physics, vol. 111, pp. 13-62, 2008.

[5] N. Saito, Y. Usui, K. Aoki et al., "Carbon nanotubes: biomaterial applications," Chemical Society Reviews, vol. 38, no. 7, pp. 1897-1903, 2009.

[6] K. Kostarelos, "The long and short of carbon nanotube toxicity," Nature Biotechnology, vol. 26, no. 7, pp. 774-776, 2008.

[7] C. A. Poland, R. Duffin, I. Kinloch et al., "Carbon nanotubes introduced into the abdominal cavity of mice show asbestoslike pathogenicity in a pilot study," Nature Nanotechnology, vol. 3, no. 7, pp. 423-428, 2008.

[8] A. Takagi, A. Hirose, T. Nishimura et al., "Induction of mesothelioma in $\mathrm{p} 53+/-$ mouse by intraperitoneal application of multi-wall carbon nanotube," Journal of Toxicological Sciences, vol. 33, no. 1, pp. 105-116, 2008.

[9] N. Kobayashi, M. Naya, M. Ema et al., "Biological response and morphological assessment of individually dispersed multi-wall carbon nanotubes in the lung after intratracheal instillation in rats," Toxicology, vol. 276, no. 3, pp. 143-153, 2010.

[10] H. Ellinger-Ziegelbauer and J. Pauluhn, "Pulmonary toxicity of multi-walled carbon nanotubes (Baytubes) relative to $\alpha$ quartz following a single $6 \mathrm{~h}$ inhalation exposure of rats and a 3 months post-exposure period," Toxicology, vol. 266, no. 13, pp. 16-29, 2009.

[11] L. Ma-Hock, S. Treumann, V. Strauss et al., "Inhalation toxicity of multiwall carbon nanotubes in rats exposed for 3 months," Toxicological Sciences, vol. 112, no. 2, pp. 468-481, 2009.

[12] D. W. Porter, A. F. Hubbs, R. R. Mercer et al., "Mouse pulmonary dose- and time course-responses induced by exposure to multi-walled carbon nanotubes," Toxicology, vol. 269, no. 2-3, pp. 136-147, 2010.

[13] J. Muller, M. Delos, N. Panin, V. Rabolli, F. Huaux, and D. Lison, "Absence of carcinogenic response to multiwall carbon nanotubes in a 2-year bioassay in the peritoneal cavity of the rat," Toxicological Sciences, vol. 110, no. 2, pp. 442-448, 2009.
[14] Bulletin NCI, 2010, http://www.cdc.gov/niosh/docket/review/ docket161a/pdfs/carbonNanotubeCIB_PublicReviewOfDraft .pdf.

[15] H. Haniu, Y. Matsuda, K. Takeuchi, Y. A. Kim, T. Hayashi, and M. Endo, "Proteomics-based safety evaluation of multi-walled carbon nanotubes," Toxicology and Applied Pharmacology, vol. 242, no. 3, pp. 256-262, 2010.

[16] H. Haniu, N. Saito, Y. Matsuda et al., "Effect of dispersants of multi-walled carbon nanotubes on cellular uptake and biological responses," International Journal of Nanomedicine, vol. 6, pp. 3295-3307, 2011.

[17] H. Haniu, N. Saito, Y. Matsuda et al., "Elucidation mechanism of different biological responses to multi-walled carbon nanotubes using four cell lines," International Journal of Nanomedicine, vol. 6, pp. 3487-3497, 2011.

[18] K. Hara, K. Aoki, Y. Usui et al., "Evaluation of CNT toxicity in comparison to tattoo ink nanoparticles for use as a biomaterial," Mater Today, vol. 14, no. 9, pp. 434-440, 2011.

[19] T. Tsukahara and H. Haniu, "Cellular cytotoxic response induced by highly purified multi-wall carbon nanotube in human lung cells," Molecular and Cellular Biochemistry, vol. 352, no. 1-2, pp. 57-63, 2011.

[20] Y. Usui, K. Aoki, N. Narita et al., "Carbon nanotubes with high bone-tissue compatibility and bone-formation acceleration effects," Small, vol. 4, no. 2, pp. 240-246, 2008.

[21] F. Liang and B. Chen, "A review on biomedical applications of single-walled carbon nanotubes," Current Medicinal Chemistry, vol. 17, no. 1, pp. 10-24, 2010.

[22] C. Ménard-Moyon, K. Kostarelos, M. Prato, and A. Bianco, "Functionalized carbon nanotubes for probing and modulating molecular functions," Chemistry and Biology, vol. 17, no. 2, pp. 107-115, 2010.

[23] X. Li, Y. Fan, and F. Watari, "Current investigations into carbon nanotubes for biomedical application," Biomedical Materials, vol. 5, no. 2, Article ID 022001, 2010.

[24] N. Saito, Y. Usui, K. Aoki et al., "Carbon nanotubes: biomaterial applications," Chemical Society Reviews, vol. 38, no. 7, pp. 1897-1903, 2009.

[25] Y. Zhang, Y. Bai, and B. Yan, "Functionalized carbon nanotubes for potential medicinal applications," Drug Discovery Today, vol. 15, no. 11-12, pp. 428-435, 2010.

[26] D. Pantarotto, J. P. Briand, M. Prato, and A. Bianco, "Translocation of bioactive peptides across cell membranes by carbon nanotubes," Chemical Communications, vol. 10, no. 1, pp. 1617, 2004.

[27] Q. Lu, J. M. Moore, G. Huang et al., "RNA polymer translocation with single-walled carbon nanotubes," Nano Letters, vol. 4, no. 12, pp. 2473-2477, 2004.

[28] A. Bianco, K. Kostarelos, C. D. Partidos, and M. Prato, "Biomedical applications of functionalised carbon nanotubes," Chemical Communications, no. 5, pp. 571-577, 2005.

[29] D. Pantarotto, R. Singh, D. McCarthy et al., "Functionalized carbon nanotubes for plasmid DNA gene delivery," Angewandte Chemie-International Edition, vol. 43, no. 39, pp. 52425246, 2004.

[30] S. Hirano, Y. Fujitani, A. Furuyama, and S. Kanno, "Uptake and cytotoxic effects of multi-walled carbon nanotubes in human bronchial epithelial cells," Toxicology and Applied Pharmacology, vol. 249, no. 1, pp. 8-15, 2010.

[31] A. O. Lobo, E. F. Antunes, M. B. S. Palma, C. Pacheco-Soares, V. J. Trava-Airoldi, and E. J. Corat, "Biocompatibility of multi-walled carbon nanotubes grown on titanium and silicon surfaces," Materials Science and Engineering C, vol. 28, no. 4, pp. 532-538, 2008. 
[32] A. O. Lobo, E. F. Antunes, A. H. A. Machado, C. PachecoSoares, V. J. Trava-Airoldi, and E. J. Corat, "Cell viability and adhesion on as grown multi-wall carbon nanotube films," Materials Science and Engineering C, vol. 28, no. 2, pp. 264 269, 2008 .

[33] A. O. Lobo, M. A. F. Corat, E. F. Antunes et al., "An evaluation of cell proliferation and adhesion on vertically-aligned multiwalled carbon nanotube films," Carbon, vol. 48, no. 1, pp. 245254, 2010.

[34] A. O. Lobo, F. R. Marciano, S. C. Ramos, M. M. MacHado, E. J. Corat, and M. A.F. Corat, "Increasing mouse embryonic fibroblast cells adhesion on superhydrophilic vertically aligned carbon nanotube films," Materials Science and Engineering C, vol. 31, no. 7, pp. 1505-1511, 2011.

[35] S. Giannona, I. Firkowska, J. Rojas-Chapana, and M. Giersig, "Vertically aligned carbon nanotubes as cytocompatible material for enhanced adhesion and proliferation of osteoblast-like cells," Journal of Nanoscience and Nanotechnology, vol. 7, no. 4-5, pp. 1679-1683, 2007.

[36] Z. Liu, S. M. Tabakman, Z. Chen, and H. Dai, "Preparation of carbon nanotube bioconjugates for biomedical applications," Nature Protocols, vol. 4, no. 9, pp. 1372-1382, 2009.

[37] N. Narita, Y. Kobayashi, H. Nakamura et al., "Multiwalled carbon nanotubes specifically inhibit osteoclast differentiation and function," Nano Letters, vol. 9, no. 4, pp. 1406-1413, 2009.

[38] X. Shi, J. L. Hudson, P. P. Spicer, J. M. Tour, R. Krishnamoorti, and A. G. Mikos, "Injectable nanocomposites of single-walled carbon nanotubes and biodegradable polymers for bone tissue engineering," Biomacromolecules, vol. 7, no. 7, pp. 2237-2242, 2006.

[39] K. Balani, R. Anderson, T. Laha et al., "Plasma-sprayed carbon nanotube reinforced hydroxyapatite coatings and their interaction with human osteoblasts in vitro," Biomaterials, vol. 28, no. 4, pp. 618-624, 2007.

[40] W. Wang, F. Watari, M. Omori et al., "Mechanical properties and biological behavior of carbon nanotube/polycarbosilane composites for implant materials," Journal of Biomedical Materials Research B, vol. 82, no. 1, pp. 223-230, 2007.

[41] L. P. Zanello, B. Zhao, H. Hu, and R. C. Haddon, "Bone cell proliferation on carbon nanotubes," Nano Letters, vol. 6, no. 3, pp. 562-567, 2006.

[42] S. Mwenifumbo, M. S. Shaffer, and M. M. Stevens, "Exploring cellular behaviour with multi-walled carbon nanotube constructs," Journal of Materials Chemistry, vol. 17, no. 19, pp. 18941902, 2007.

[43] T. Akasaka, F. Watari, Y. Sato, and K. Tohji, "Apatite formation on carbon nanotubes," Materials Science and Engineering C, vol. 26, no. 4, pp. 675-678, 2006

[44] B. Zhao, H. Hu, S. K. Mandal, and R. C. Haddon, "A bone mimic based on the self-assembly of hydroxyapatite on chemically functionalized single-walled carbon nanotubes," Chemistry of Materials, vol. 17, no. 12, pp. 3235-3241, 2005.

[45] J. M. Wörle-Knirsch, K. Pulskamp, and H. F. Krug, "Oops they did it again! Carbon nanotubes hoax scientists in viability assays," Nano Letters, vol. 6, no. 6, pp. 1261-1268, 2006.

[46] A. Casey, E. Herzog, M. Davoren, F. M. Lyng, H. J. Byrne, and G. Chambers, "Spectroscopic analysis confirms the interactions between single walled carbon nanotubes and various dyes commonly used to assess cytotoxicity," Carbon, vol. 45, no. 7, pp. 1425-1432, 2007.

[47] T. Tsukahara and H. Haniu, "Nanoparticle-mediated intracellular lipid accumulation during $\mathrm{C} 2 \mathrm{C} 12$ cell differentiation," Biochemical and Biophysical Research Communications, vol. 406, no. 4, pp. 558-563, 2011.
[48] M. P. Mattson, R. C. Haddon, and A. M. Rao, "Molecular functionalization of carbon nanotubes and use as substrates for neuronal growth," Journal of Molecular Neuroscience, vol. 14, no. 3, pp. 175-182, 2000.

[49] Y. Ni, H. Hu, E. B. Malarkey et al., "Chemically functionalized water soluble single-walled carbon nanotubes modulate neurite outgrowth," Journal of Nanoscience and Nanotechnology, vol. 5, no. 10, pp. 1707-1712, 2005.

[50] K. Matsumoto, C. Sato, Y. Naka, A. Kitazawa, R. L. D. Whitby, and N. Shimizu, "Neurite outgrowths of neurons with neurotrophin-coated carbon nanotubes," Journal of Bioscience and Bioengineering, vol. 103, no. 3, pp. 216-220, 2007.

[51] R. A. Dubin, G. C. Callegari, J. Kohn, and A. V. Neimark, "Carbon nanotube fibers are compatible with mammalian cells and neurons," IEEE Transactions on Nanobioscience, vol. 7, no. 1, pp. 11-14, 2008.

[52] X. Luo, C. L. Weaver, D. D. Zhou, R. Greenberg, and X. T. Cui, "Highly stable carbon nanotube doped poly(3,4ethylenedioxythiophene) for chronic neural stimulation," Biomaterials, vol. 32, no. 24, pp. 5551-5557, 2011.

[53] H. Hu, Y. Ni, S. K. Mandal et al., "Polyethyleneimine functionalized single-walled carbon nanotubes as a substrate for neuronal growth," Journal of Physical Chemistry B, vol. 109, no. 10, pp. 4285-4289, 2005.

[54] H. Haniu, N. Saito, Y. Matsuda et al., "Manufacturing strategy for multiwalled carbon nanotubes as a biocompatible and innovative material," Journal of Nanotechnology, vol. 2012, Article ID 937819, 6 pages, 2012.

[55] X. Li, H. Gao, M. Uo et al., "Maturation of osteoblast-like SaoS2 induced by carbon nanotubes," Biomedical Materials, vol. 4, no. 1, Article ID 015005, 2009.

[56] X. Li, H. Gao, M. Uo et al., "Effect of carbon nanotubes on cellular functions in vitro," Journal of Biomedical Materials Research A, vol. 91, no. 1, pp. 132-139, 2009.

[57] Y. Cao, Y. M. Zhou, Y. Shan, H. X. Ju, and X. J. Xue, "Preparation and characterization of grafted collagen-multiwalled carbon nanotubes composites," Journal of Nanoscience and Nanotechnology, vol. 7, no. 2, pp. 447-451, 2007.

[58] R. A. MacDonald, B. F. Laurenzi, G. Viswanathan, P. M. Ajayan, and J. P. Stegemann, "Collagen-carbon nanotube composite materials as scaffolds in tissue engineering," Journal of Biomedical Materials Research A, vol. 74, no. 3, pp. 489-496, 2005.

[59] Z. Tosun and P. S. McFetridge, "A composite SWNT-collagen matrix: characterization and preliminary assessment as a conductive peripheral nerve regeneration matrix," Journal of Neural Engineering, vol. 7, no. 6, Article ID 66002, 2010.

[60] W. Tan, J. Twomey, D. Guo, K. Madhavan, and M. Li, "Evaluation of nanostructural, mechanical, and biological properties of collagennanotube composites," IEEE Transactions on Nanobioscience, vol. 9, no. 2, Article ID 5427121, pp. 111-120, 2010.

[61] A. O. Lobo, E. F. Antunes, M. B. Palma, C. Pacheco-Soares, V. J. Trava-Airoldi, and E. J. Corat, "Monolayer formation of human osteoblastic cells on vertically aligned multiwalled carbon nanotube scaffolds," Cell Biology International, vol. 34, no. 4, pp. 393-398, 2010.

[62] A. O. Lobo, M. A. F. Corat, E. F. Antunes, M. B. S. Palma, C. Pacheco-Soares, and E. J. Corat, "Cytotoxicity analysis of vertically aligned multi-walled carbon nanotubes by colorimetric assays," Synthetic Metals, vol. 159, no. 21-22, pp. 21652166, 2009.

[63] A. O. Lobo, M. A. F. Corat, E. F. Antunes, S. C. Ramos, C. Pacheco-Soares, and E. J. Corat, "Cytocompatibility studies of 
vertically-aligned multi-walled carbon nanotubes: raw material and functionalized by oxygen plasma," Materials Science and Engineering C, vol. 32, no. 4, pp. 648-652, 2012.

[64] D. Zhang, M. A. Kandadai, J. Cech, S. Roth, and S. A. Curran, "Poly(L-lactide) (PLLA)/multiwalled carbon nanotube (MWCNT) composite: characterization and biocompatibility evaluation," Journal of Physical Chemistry B, vol. 110, no. 26, pp. 12910-12915, 2006.

[65] S. D. McCullen, D. R. Stevens, W. A. Roberts et al., "Characterization of electrospun nanocomposite scaffolds and biocompatibility with adipose-derived human mesenchymal stem cells," International Journal of Nanomedicine, vol. 2, no. 2, pp. 253-263, 2007.

[66] J. Meng, H. Kong, Z. Han et al., "Enhancement of nanofibrous scaffold of multiwalled carbon nanotubes/polyurethane composite to the fibroblasts growth and biosynthesis," Journal of Biomedical Materials Research A, vol. 88, no. 1, pp. 105-116, 2009.

[67] D. Meng, S. N. Rath, N. Mordan, V. Salih, U. Kneser, and A. R. Boccaccini, "In vitro evaluation of 45S5 Bioglass-derived glassceramic scaffolds coated with carbon nanotubes," Journal of Biomedical Materials Research A, vol. 99A, no. 3, pp. 435-444, 2011.

[68] A. Abarrategi, M. C. Gutiérrez, C. Moreno-Vicente et al., "Multiwall carbon nanotube scaffolds for tissue engineering purposes," Biomaterials, vol. 29, no. 1, pp. 94-102, 2008.

[69] C. W. Lam, J. T. James, R. McCluskey, and R. L. Hunter, "Pulmonary toxicity of single-wall carbon nanotubes in mice 7 and 90 days after intractracheal instillation," Toxicological Sciences, vol. 77, no. 1, pp. 126-134, 2004.

[70] J. Muller, F. Huaux, N. Moreau et al., "Respiratory toxicity of multi-wall carbon nanotubes," Toxicology and Applied Pharmacology, vol. 207, no. 3, pp. 221-231, 2005.

[71] A. A. Shvedova, E. R. Kisin, R. Mercer et al., "Unusual inflammatory and fibrogenic pulmonary responses to single-walled carbon nanotubes in mice," American Journal of PhysiologyLung Cellular and Molecular Physiology, vol. 289, no. 5, pp. L698-L708, 2005.

[72] D. B. Warheit, B. R. Laurence, K. L. Reed, D. H. Roach, G. A. M. Reynolds, and T. R. Webb, "Comparative pulmonary toxicity assessment of single-wall carbon nanotubes in rats," Toxicological Sciences, vol. 77, no. 1, pp. 117-125, 2004.

[73] N. Garmendia, I. Santacruz, R. Moreno, and I. Obieta, "Zirconia-MWCNT nanocomposites for biomedical applications obtained by colloidal processing," Journal of Materials Science: Materials in Medicine, vol. 21, no. 5, pp. 1445-1451, 2010.

[74] G. D. Zhan, J. D. Kuntz, J. Wan, and A. K. Mukherjee, "Singlewall carbon nanotubes as attractive toughening agents in alumina-based nanocomposites," Nature Materials, vol. 2, no. 1, pp. 38-42, 2003.

[75] J. A. Arsecularatne and L. C. Zhang, "Carbon nanotube reinforced ceramic composites and their performance," Recent patents on nanotechnology, vol. 1, no. 3, pp. 176-185, 2007.

[76] R. R. Mercer, A. F. Hubbs, J. F. Scabilloni et al., "Distribution and persistence of pleural penetrations by multi-walled carbon nanotubes," Particle and Fibre Toxicology, vol. 7, article no. 28, 2010.

[77] H. Nagai, Y. Okazaki, S. H. Chew et al., "Diameter and rigidity of multiwalled carbon nanotubes are critical factors in mesothelial injury and carcinogenesis," Proceedings of the National Academy of Sciences of the United States of America, vol. 108, no. 49, pp. E1330-E1338, 2011.
[78] V. C. Sanchez, P. Weston, A. Yan, R. H. Hurt, and A. B. Kane, "A 3-dimensional in vitro model of epithelioid granulomas induced by high aspect ratio nanomaterials," Particle and Fibre Toxicology, vol. 8, article 17, 2011.

[79] X. Liu, R. H. Hurt, and A. B. Kane, "Biodurability of singlewalled carbon nanotubes depends on surface functionalization," Carbon, vol. 48, no. 7, pp. 1961-1969, 2010. 

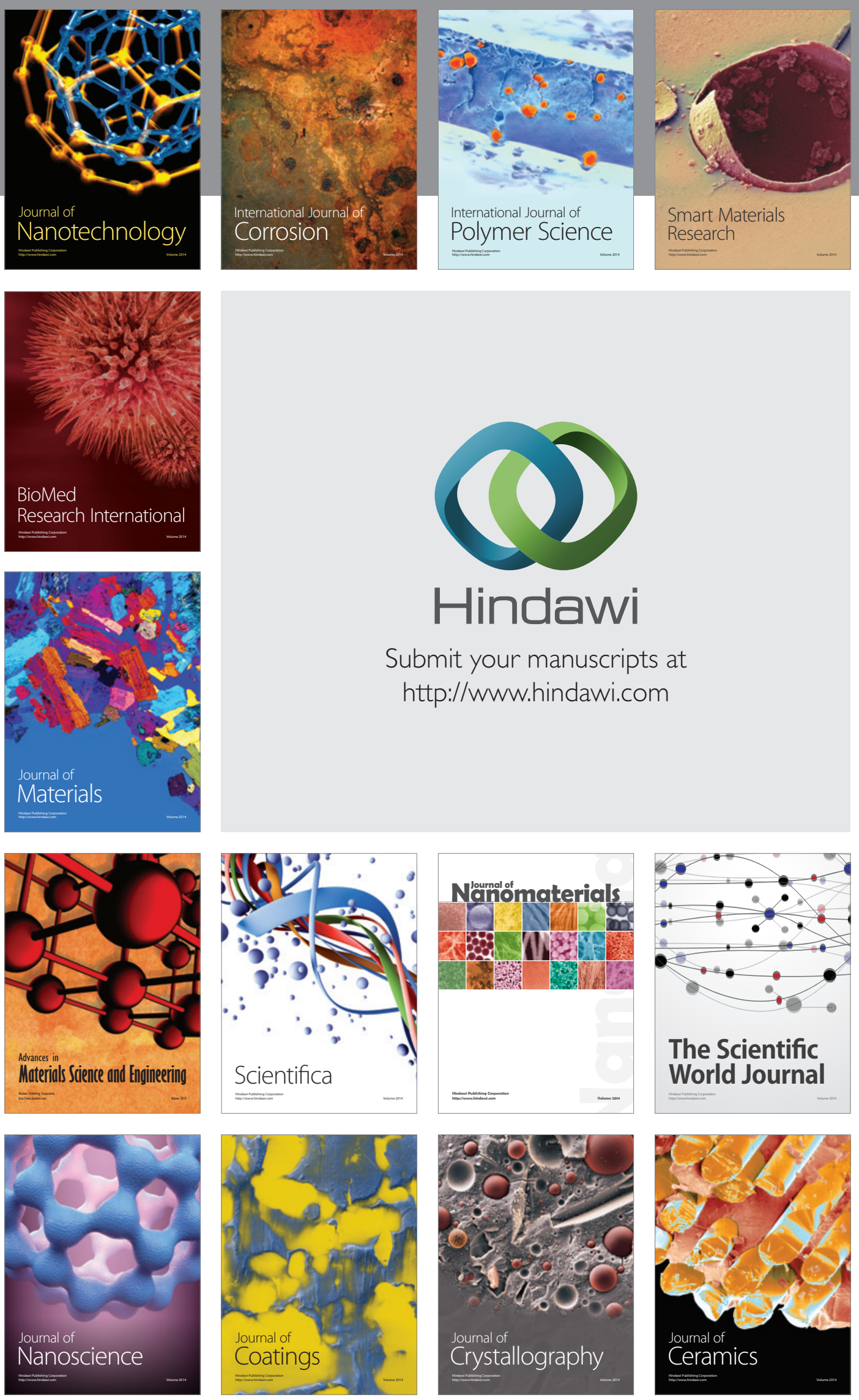

The Scientific World Journal

Submit your manuscripts at

http://www.hindawi.com

\section{World Journal}

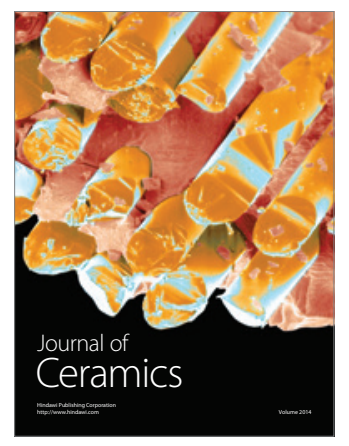

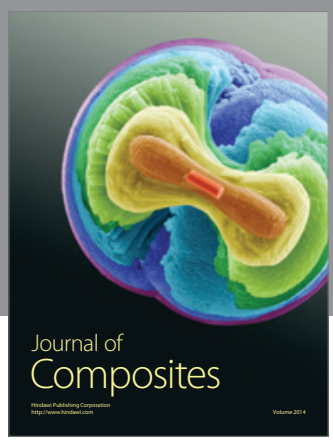
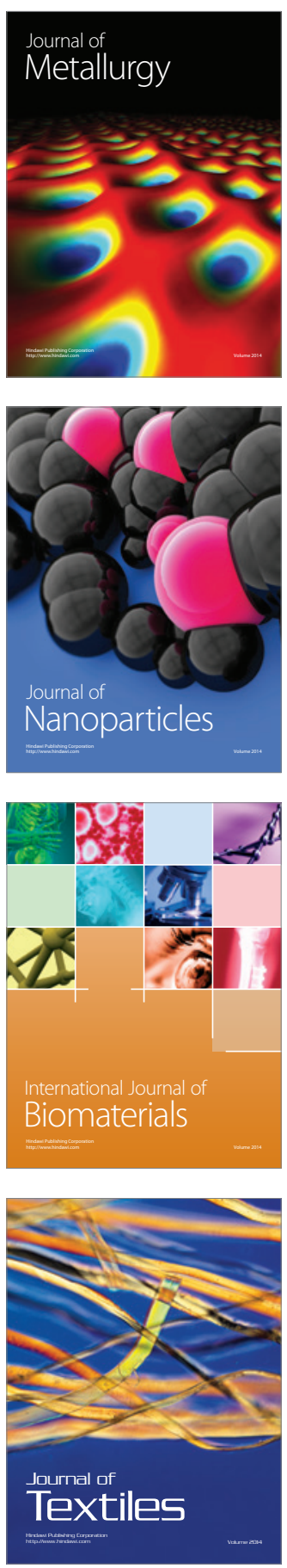